\title{
The Influence of Framing Effects on Consumer Decision-Making on Online Platforms
}

\author{
Yiyang $\mathrm{Hu}^{1} \&$ Yixuan $\mathrm{Li}^{1}$ \\ ${ }^{1}$ RDFZ Chaoyang Branch School, Sun Palace North Street No.5, Beijing, China \\ Correspondence: Yiyang Hu, RDFZ Chaoyang Branch School, Sun Palace North Street No.5, Beijing, China. Tel: \\ 86-10- 84296311. E-mail: huyiyang @ rdfzcygj.cn
}

Received: February 18, 2019

Accepted: March 8, 2019

Online Published: March 13, 2019

doi:10.5430/bmr.v8n1p30

URL: https://doi.org/10.5430/bmr.v8n1p30

\begin{abstract}
Focusing on online electronics sales and online travel service customization, the present research employed two experiments to examine the framing effects on consumer decision making in the context of internet marketing. Study1 showed that combined (vs. partitioned) pricing strategy can promote consumers' purchase intention on e-commerce platforms. Study 2 demonstrated that downgrade (vs. upgrade) framing approach can lead to higher total sum price and less change on the default package in travel package customization settings. The results have significantly implications for marketing management in the context of internet marketing.
\end{abstract}

Keywords: framing effect, prospect theory, consumer decision-making, online platforms

\section{Introduction}

With internet extending into every aspects of living, consumers' purchase behavior gradually shifts from offline to online. E-commerce platforms like Taobao Tmall, Jingdong Mall, online travel agencies like Ctrip, Tuniu and other forms of online platforms gradually cover all aspects of people's lives. A latest survey shows that the number of people shopping online in China has increased to 569 million in June 2018. Moreover, the total online retail transactions in China in the first half of 2018 has reached 408 billion yuan. Furthermore, the number of users in online travel platform has increased to 392 million while that of online booking leisure resort products has increased by $9.7 \%$, accounting for $12.1 \%$ of the total netizens. The prevalence of network consumption calls for research on how different factors affect individuals' purchase behavior

Consumers usually notice that the same products have different pricing methods when shopping online. Specifically, some products show the price in a combined way including product price and postage together, but others display product price and the mailing price separately. On the online travel booking platform, it is noticed that the default options offered by some travel agencies are luxury packages while those offered by other travel agencies are economic packages. We are wondering how these different pricing methods will influence consumers' decision-making behaviors.

From prospect theory, we know that the presentation form has significant impact on consumer decision-making behavior which is called framing effect. Framing effect is defined as "different descriptions of an objectively identical problem lead to different decision-making outcomes" (Tversky \& Kahneman, 1981). Since its first literary description in 1981, it has attracted considerable attention by scholars. For example, research have found that using positive way (such as $75 \%$ lean) or negative way ( $25 \%$ fat) by supermarkets to display meat information can affect consumers' perception of meat quality (Levin \& Gaeth 1988). Luluo Peng (2012) found that the two essentially identical expressions of "7 zhe" and " $30 \%$ off" will trigger different perceptions. Research of framing effect has a long history, however, most of the existing research focuses on offline product sales, rare research has focused on the network platform, especially the network travel platform.

Using two studies, the current research examined the specific impact of the framework effect on consumer decision-making behavior in the context of online shopping and online service customization. Study 1 examined how the pricing strategies (combined vs. partitioned) affects consumers' purchasing intentions on e-commerce platforms. Study 2 examined how the customization methods of travel product (upgrade vs. downgrade) influence the total package price and consumer satisfaction on online travel agency platform. By covering both product and service, this research presents a more comprehensive picture of the influence of framework effect on consumer perception and 
decision-making in the context of network.

\section{Study1: Pricing Strategy of Online Electronics Sales}

\subsection{Theoretical Background}

In classical economics, individuals' decision-making is seen as absolutely rational, that is, individuals make the most perfect decision based on existing information. However, in cognitive psychology it is believed that individual decision-making is not completely determined by external stimuli, and the internal psychological process also plays an important role.

The core point of prospect theory (Kahneman \& Tversky, 1979) is that people's state of gains or losses can cause individuals to react differently. In prospect theory, value function describes the change in individuals' subjective perceived value in the state of loss or gain. The value function is an S-type curve (see Figure 1), with the actual loss and gain as the independent variable, the perceived value as the dependent variable.

The function in the gain state is a convex function while in the loss state the function is a concave function. It is notable that the slope of the concave function is larger than the convex function which indicates loss aversion. Loss aversion is the core inference of value function, that is, for the same amount of gains and losses people are more sensitive to losses. Therefore, people will try to avoid losses when making decisions.

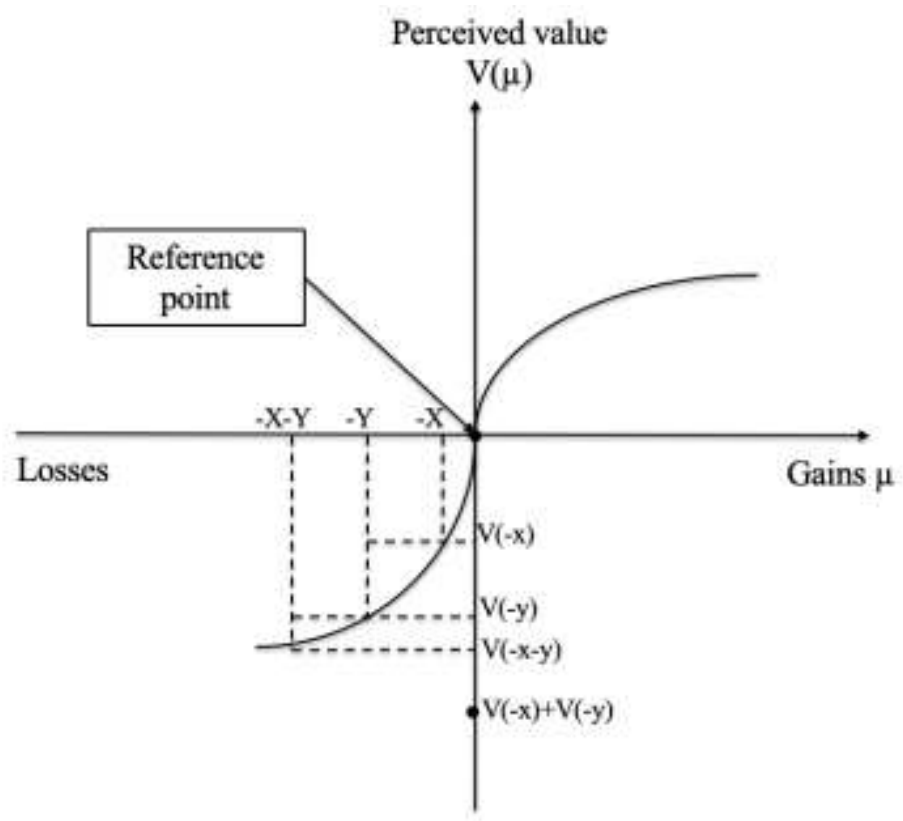

Figure 1. Value function

Based on the prospect theory, Thaler (1985) proposed the theory of mental accounting. Mental accounting refers to the psychological process that classifies money into different accounts and values them differently (Thaler, 1985). People place money into multiple separate sub-accounts based on income sources, expenditure items, or storage methods. Thaler (1985) believes that while making a decision, people use psychological calculations to evaluate the losses vs. gains of each account. After the psychological process, individuals obtain the perceived value of the gains and losses of each account and make decisions based on it.

\subsection{Hypothesizes Development}

Compared with other attributes of goods, the price is the most obvious and concerned one. Combined pricing and partitioned pricing are two opposing pricing strategies. Combined pricing refers to charging a single price that includes all fees. For example, the e-commerce platform packages the price of the product and the cost of postage into a single price. Partitioned pricing refers to the strategy that divides a product's price into a base price (for the product itself) and a mandatory surcharge(s) for postage, taxes or other services. For example, the e-commerce platform presents the cost of the product and the cost of the postage separately. These two pricing strategies have the 
same total price and there is no difference between them in essence.

When the product is presented using combined pricing, the payment for the product itself and the cost of postage are included in the same mental account as a single loss. When the goods are presented using partitioned pricing, the payment for the product itself and the cost of the postage are put into two mental accounts. Therefore, there are two losses with one is for the product itself and the other is for the mailing fee. Now assume that the losses caused by these two expenditures are expressed as $-\mathrm{X}$ and $-\mathrm{Y}$, respectively. If we assume individuals as absolutely rational, no matter the two expenditures are spent together or separately, consumers will make the same decision with no difference. However, according to characteristics of the value function (refer to Figure 1), in the loss part, the value function is a concave function, thus $\mathrm{V}(-\mathrm{X})+\mathrm{V}(-\mathrm{Y})<\mathrm{V}(-\mathrm{X}-\mathrm{Y})$. That is, under the influence of the mental account, when the price is divided into two separate prices, individuals' sense of loss is much stronger than that under combined pricing. Therefore, we can infer that under the role of mental accounting, consumers prefer the option with less loss when they choose between combined pricing and partitioned pricing. Therefore, we propose the following assumptions:

H1: Consumers perceive combined pricing as more attractive than partitioned pricing in the context of online shopping. Specifically, consumers have higher purchase intention for the product using combined pricing (vs. partitioned pricing).

\subsection{Method}

\subsubsection{Participants and Stimuli}

Study1 was used to test H1, that is, consumers are more willing to purchase when an e-commerce platform using the combined pricing method than when using the separate pricing method. A total of 149 students $(45.64 \%$ male, 54.36\% female) from a high school in Beijing participated in the experiment. The age range was mainly between 15 and 18 years old while the average monthly consumption is below 2,000 $¥$. See Table 1 for details.

Table 1. Demographic Information in Study1

\begin{tabular}{cccc}
\hline & Gender & Age range & $\begin{array}{c}\text { Average Consumption } \\
\text { per month }\end{array}$ \\
\hline & Male & $15 \sim 16$ & $<1000 ¥$ \\
Number & $68(45.6 \%)$ & $89(59.7 \%)$ & $56(37.6 \%)$ \\
and & Female & $17 \sim 18$ & $1001 ¥ \sim 2000 ¥$ \\
Percentage & $81(54.4 \%)$ & $45(30.2 \%)$ & $50(33.5 \%)$ \\
& & $>19$ & $>2000 ¥$ \\
& & $15(10.1 \%)$ & $43(28.9 \%)$ \\
\hline
\end{tabular}

In order to minimize the influence of product familiarity, we chose a charging pal that consumers are familiar with as experimental stimuli. Also, in order to avoid the influence of brand familiarity, this experiment hid the brand name. We only told the participants that it is a charging pal sold on Tmall Mall. We designed the experiment in advance based on the real charging pal information on the online shopping platform. We designed two kinds of product information pages. In one condition, the price was separately divided into the product price and the mailing fee. In the other condition, the price included the product price and the mailing fee. In the two product information webpages, except for the pricing presentation method, the remaining product information such as the total price, the charging material, the shape, and the charging capacity were all the same. Participants saw these two types of product information webpages in turn and then were asked to answer the willingness to purchase between these two.

\subsubsection{Procedure}

Participants were first asked to answer two questions on the basic information about charging pal. The first question was "If you plan to buy a charging pal now, what are the main factors to consider when purchasing (multiple choice)" while the options were capacity, design, material, price and so on. The second question was "If you plan to buy a charging pal, the price level you can accept is_?" while the option includes "100 $¥$ or less", "100 $¥-200 ¥ ”, ~ " 200$ $¥-300 ¥ "$ and "300 $¥$ or more". These two questions were used to understand some of the basic ideas of the participants in purchasing the charging pal. 
After that, we asked the participants to read and imagine the following situation: "Now you are considering purchasing a charging pal to charge your mobile phone when traveling. You log in to Tmall Mall and enter some of the conditions you need (charge capacity, aluminum alloy metal case), shape and thickness, fast charging method, etc.), and then you find a charging pal made by a well-known manufacturer". Next, participants saw the two online shopping webpages of charging pal. The pictures of the charging pal on the two pages were the same as also as the following information: product selling point "two-way fast charging only $12.58 \mathrm{~mm}$ thin", color "golden", and monthly sales volume "10594", cumulative evaluation "66674". The difference was that one pricing was displayed as "price $¥ 141$, express delivery fee $¥ 8$ ", and the other one pricing method was displayed as " $¥ 149$ (including express delivery fee)".

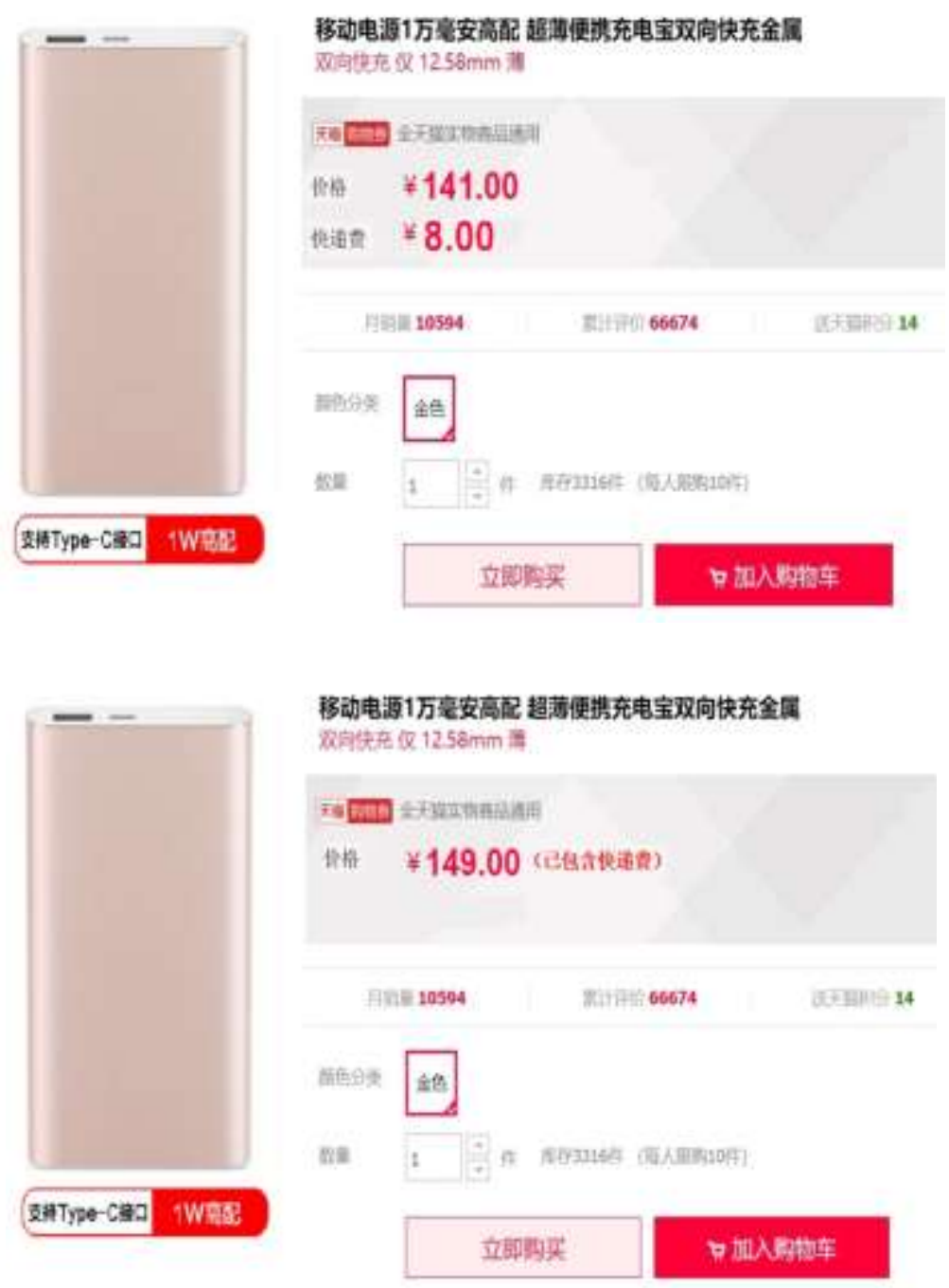

Figure 2. Description of two Pricing Strategies (partitioned pricing above, combined pricing below)

After reviewing the product information, the participants answered the following two questions: (1) Please choose one option to purchase; (2) Your preference between these two options. The second question used a seven-point scale. The higher the score, the more likely it is to buy option 2. The lower the score, the more likely it is to buy option 1 ( 1 = option 1, 7 = option 2). Finally, the participants reported demographic information. 


\subsubsection{Results}

From Figure 3, we can see that the top three factors that the participants concern most when purchasing charging pal are the charging capacity $(93.96 \%)$, the price level (72.48) and the charging speed (62.42\%). As can be seen from Figure 4, when purchasing a charging pal, the number of people whose acceptable price ranging from $100 ¥$ to 199 $¥$ is the most.

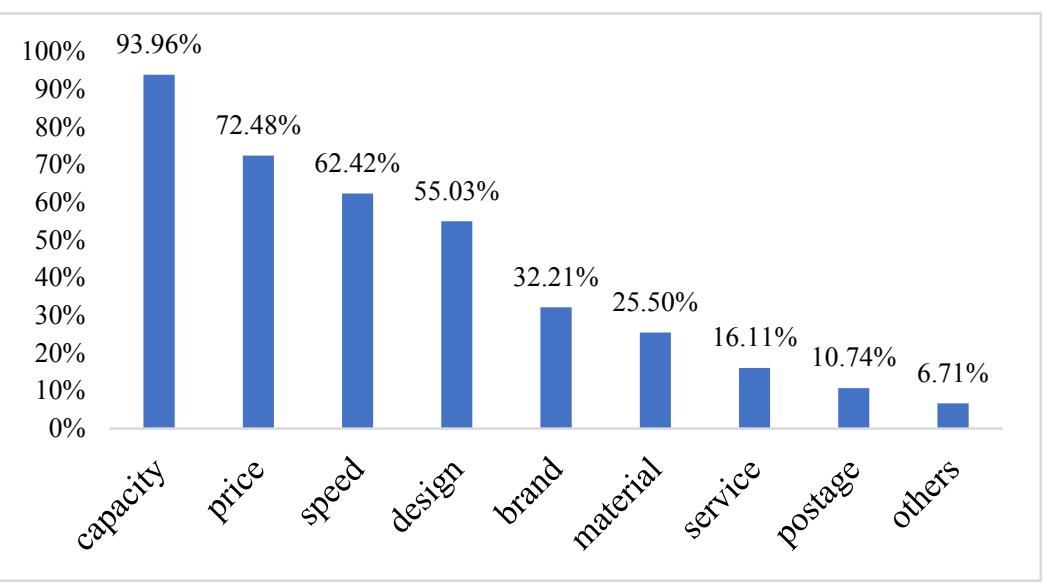

Figure 3. Percentage of Factors to Be Consider

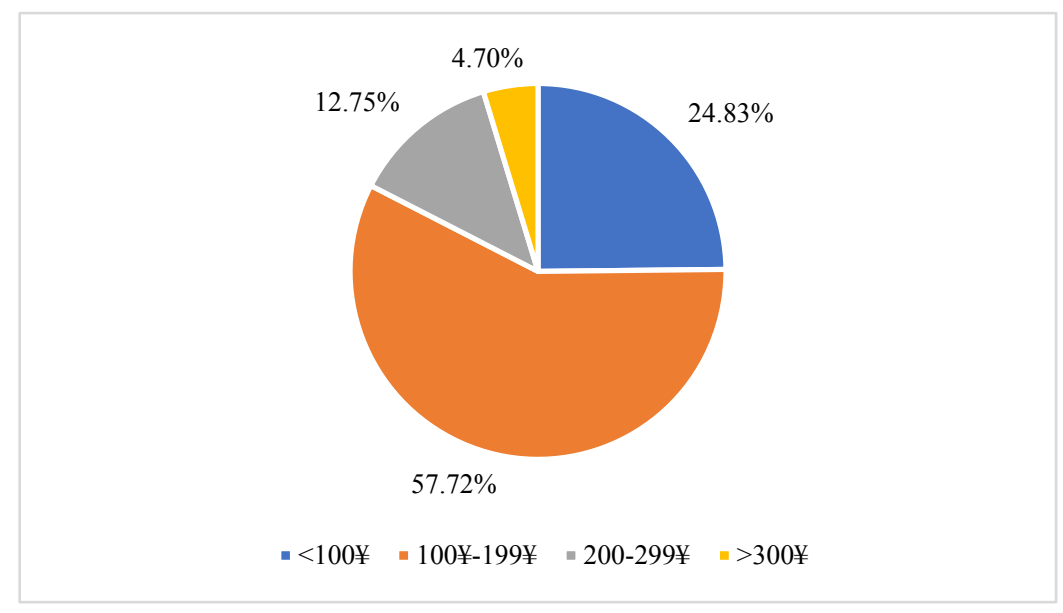

Figure 4. Percentage of Acceptable Price Range

Next, we tested H1. The results showed that of the 149 participants, 45 chose to purchase under the partitioned pricing strategy and 104 chose to purchase under the combined pricing strategy. Also, the results show (see Figure 5) that there is a significant difference in the purchasing tendency between the two condition, that is, consumers are more likely to purchase charging pal under the combined pricing scheme than the partitioned pricing scheme $(M$ partitioned $=3.00$ vs $M$ combined $=5.09, t=9.73, p<0.001)$. The results indicate that different product pricing methods can affect the individual's purchase intention and H1 was supported. There is no significant difference in decision response time (unit: second) $(M$ separation $=78.33$ vs. $M$ integration $=88.69, t=-0.78, p>0.4)$. Detailed data are shown in Table 2. 
Table 2. Main Result in Study1

\begin{tabular}{cccccc}
\hline $\begin{array}{c}\text { Pricing } \\
\text { Strategy }\end{array}$ & Number & Gender Ratio & $\begin{array}{c}\text { Acceptable } \\
\text { price range }\end{array}$ & $\begin{array}{c}\text { Purchase } \\
\text { intention }\end{array}$ & $\begin{array}{c}\text { Time } \\
\text { (second) }\end{array}$ \\
\hline Partitioned & 104 & male44/female60 & 2.03 & 5.09 & 88.69 \\
Combined & 45 & male24/female21 & 1.84 & 3.00 & 78.33 \\
Significance & & & $t=1.38 p>0.1$ & $\begin{array}{c}t=9.73 \\
p<0.001\end{array}$ & $\begin{array}{c}t=0 .-78 \\
p>0.1\end{array}$ \\
\hline
\end{tabular}

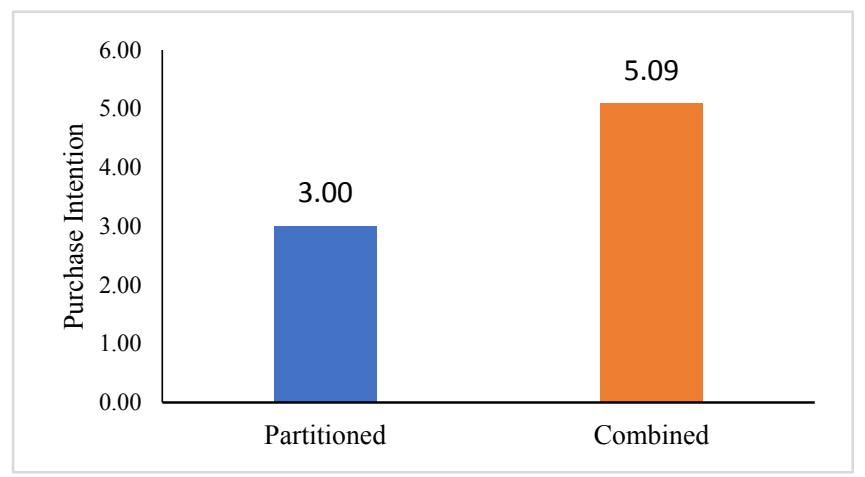

Figure 5. Purchase intention under different pricing strategy

We examined the moderating role of gender. In terms of purchase intention, the covariance results showed that there no moderation effects of gender (male vs. female) on the effect of pricing strategy on purchase intention $(F(1,145)=$ $0.87, p>0.3$ ). Then, we examined the moderating role of consumption levels. The covariance results showed that there was no moderation effect of consumption level (high vs. low) on the effect of pricing strategy on purchase intention $(F(1,145)=1.86, p>0.1)$. The detailed results are shown in Table 3 .

Table 3. Results of Moderation Effects

\begin{tabular}{ccccc}
\hline $\begin{array}{c}\text { Pricing } \\
\text { Strategy }\end{array}$ & \multicolumn{2}{c}{ Purchase Intention } & \multicolumn{2}{c}{ Purchase Intention } \\
& Male & Female & $\begin{array}{c}\text { High } \\
\text { consumption }\end{array}$ & $\begin{array}{c}\text { Low } \\
\text { consumption }\end{array}$ \\
\hline Combined & 5.11 & 5.07 & 5.17 & 5.05 \\
Partitioned & 2.83 & 3.19 & 2.64 & 3.16 \\
Significance & $\mathrm{t}=-7.17$ & $\mathrm{t}=-6.36$ & $\mathrm{t}=-5.66$ & $\mathrm{t}=-7.87$ \\
& $\mathrm{p}<0.0001$ & $\mathrm{p}<0.0001$ & $\mathrm{p}<0.0001$ & $\mathrm{p}<0.0001$ \\
Moderation & $\mathrm{F}(1,145)=0.87 \mathrm{p}>0.3$ & $\mathrm{~F}(1,145)=1.86 \mathrm{p}>0.1$ \\
\hline
\end{tabular}

\section{Study2: Online Travel Service Customization}

\subsection{Theoretical Background}

Reference dependence refers to the fact that people's subjective judgment on a decision result is relative to a reference point. People's perceived value of things depends on the relative difference between the actual value of the thing and the reference point. People make decisions based on the perceived value (perceived gains or perceived loss). Thaler proposed the endowment effect in 1980. The core implication is that when a person owns something, he/she values it more than if he/she does not have it. For the seller, giving up the item means losing money and 
getting money means income; for the buyer, losing money is a loss, and obtaining the item is a benefit. In view of the fact that pain induced by loss is more intense than the happiness induced by gain, in order to minimize the pain caused by the loss, the seller is more willing to raise the selling price and the buyer is more likely to lower the purchase price.

\subsection{Hypothesis Development}

In the context of internet environment, companies use customized ways while providing services and consumers can design services according to their own needs within the framework given by marketers. Park, Jun \& Macinnis (2000) have found that customization method can affect individual decision outcomes. For example, when a consumer deletes an unwanted item based on the full model, the price of the package is set to be higher than that of the package when the desired item is added based on the base model. In addition to addition/subtraction, the upgrade/downgrade framing approach is also a popular customization method. Upgrade framing approach refers to asking consumers to adjust the default options by upgrading the low-end setting. Downgrade framing approach refers to asking consumers to adjust the default options by degrading the high-end setting. For example, in the travel customization, a four-star hotel can be upgraded to a five-star or be downgraded to a three-star in different framing approach. When purchasing a computer, a computer with $128 \mathrm{G}$ memory can be upgraded to $256 \mathrm{G}$ memory or be degraded to $64 \mathrm{G}$ memory.

We propose that in the service customization, different customization methods namely the upgrade framing approach based on the economic package or degrade framing approach based on the advanced package will influence individual customization behavior. According to the prospect theory, when a consumer needs to add certain items or upgrade certain service attributes level based on an economical package, the consumer is "losing" money. When a consumer deletes certain items or downgrades certain service attribute level based on an advanced package, the consumer is "getting" money. Since the pain caused by the loss of the same amount of money is far greater than the happiness of obtaining the same amount of money, consumers are more unwilling to upgrade the options. In addition, according to the endowment effect, when the options customization was framed using upgrade approach, the default advanced package will be easily seen as things that consumers own already. When consumers need to delete or downgrade certain service items on this basis, they will give higher valuations to these services psychologically. If these items are deleted or downgraded, they will have a stronger sense of loss. Therefore, the tendency to delete or downgrade will be very low which leads to a higher total sum price. Based on the above, we propose the following assumptions:

H2: In travel customization, compared to the upgrade framing approach based on the economic package, the total price of the downgrade framing approach based on the advanced package is higher.

\subsection{Method}

\subsubsection{Participants and Stimuli}

The purpose of experiment 2 is to test H2. A total of 117 MBA (male $69.2 \%$ vs. female $30.8 \%$ ) students from a university in Beijing participated in the experiment. Among them, the average number of trips per year is 3.4 times, the average cost per travel is $7,000 ¥$ to $10,000 ¥$, and the monthly per capita consumption is 10,000 to $15,000 ¥$. The detailed demographic information of the participants is shown in Table 4.

Table 4. Demographic Information in Study2

\begin{tabular}{|c|c|c|c|c|c|}
\hline & Gender & $\begin{array}{c}\text { Age } \\
\text { Range }\end{array}$ & $\begin{array}{c}\text { Annual travel } \\
\text { times }\end{array}$ & $\begin{array}{c}\text { Annual travel } \\
\text { expenses }\end{array}$ & $\begin{array}{l}\text { Expenses per } \\
\text { month }\end{array}$ \\
\hline \multirow{8}{*}{$\begin{array}{l}\text { Number and } \\
\text { Percentage }\end{array}$} & Male & $<=30$ & $<=1$ & $<=2000 ¥$ & $<5000 ¥$ \\
\hline & $81(69.2 \%)$ & $18(15.4 \%)$ & $33(28.2 \%)$ & $1(0.9 \%)$ & $13(11.1 \%)$ \\
\hline & \multirow{6}{*}{$\begin{array}{c}\text { Female } \\
36(30.8 \%)\end{array}$} & $31 \sim 35$ & $2 \sim 4$ & $2001 ¥ \sim 8000 ¥$ & $5001 \sim$ \\
\hline & & $54(46.2 \%)$ & $74(63.2 \%)$ & $50(42.7 \%)$ & \\
\hline & & $36 \sim 40$ & $>5$ & $>8000 ¥$ & $15001 ¥ \sim 30000 ¥$ \\
\hline & & $37(31.6 \%)$ & $10(8.5 \%)$ & $66(56.4 \%)$ & $25(21.4 \%)$ \\
\hline & & $>40$ & & & $>30000 ¥$ \\
\hline & & $8(6.8 \%)$ & & & $13(11.1 \%)$ \\
\hline
\end{tabular}


The experiment used a single factor between-subjects design (customized framing approach: downgrade approach based on an advanced package vs. upgraded approach based on economic package). Before the experiment, we designed two versions (luxury package and economic package) of the "Sanya Four Days and Three Nights Tour" travel service package from Beijing based on the real travel product information of a travel website, namely advanced package, and economic package. Both packages included round-trip airfare, hotel accommodation, travel itineraries and play items, with only differences in consumption levels of default options. For example, as for the round-trip ticket, there were two options: "Beijing-Sanya fly-to-fly (3600 yuan)" and "Beijing-Sanya transfer/Hefei transfer (3100 yuan)". In the advanced package, the option "Beijing-Sanya fly-to-fly (3600 yuan)" was ticked whereas in the economic package, the option "Beijing-Sanya transfer/Hefei transfer (3100 yuan)" was ticked.

It is notable that when the luxury travel package was downgraded to the lowest level, it was the same as the economic travel package. When the economic travel package was upgraded to the highest level, it was the same as the luxury travel package. In the luxury package, the service customization approach was to downgrade/subtract based on the luxury package. Once a service item was downgraded or deleted, the corresponding fee was reduced. In the economic package, the service customization approach was to upgrade/add based on the economic package. Each time the service item was upgraded/added, the corresponding cost increases.

\subsubsection{Procedure}

The participants were required to imagine that they are going to travel to Sanya from Beijing during the National Day holiday from September 29 to October 2. Participants in the downgrade framing condition were told that the travel agency recommended a "Sanya Four Days and Three Nights Tour" luxury package $(\$ 8,330)$. Also, they can customize the service online based on it, i.e. to delete unwanted items or to reduce service grade. Participants in the upgrade framing condition were told that the travel agency recommended a "Sanya Four Days and Three Nights Tour" economic package $(\$ 4,940)$ which they can use to customize the service online according to their own needs. The maximum times that participants can upgrade or downgrade is 9 times. The options can be adjusted include air ticket (direct flight or transfer via Hefei), accommodation hotel (five-star or four-star), performance seat (private seat or regular seat) in the first day, the four activities in Wuzhizhou Island (coral island diving, underwater walk, land surfing, motorboat round-the-island project participation) in the second day, the activities involved in Tianya Haijiao and Nanshan Foyuan scenic area in the third day, and activities involved in Noda Rainforest Scenic in the fourth day( visit Butterfly Pavilion project).

After completing the trip customization, the participants answered questions on the satisfaction of the decision-making process and the decision-making results $(1=$ satisfaction $5=$ dissatisfaction $)$, and whether they would like to recommend to classmates and friends $(1=$ willing $5=$ unwilling $)$. Finally, the participants answered questions about demographic information such as gender, age, monthly consumption amount, average annual travel times, and average cost per trip.

\subsubsection{Results}

The data showed that in terms of the number of change times, participants in downgrade framing condition made an average of 2.87 reductions and replacements based on the luxury package. In contrast, participants in the upgrade framing condition have done an average of 5.09 upgrades and replacements in the customization process. The difference in the number of change times is significant $(t=5.42, \mathrm{p}<0.001)$. This shows that due to the loss of aversion and endowment effects, consumers under the downgrade customization framing approach are more reluctant to make changes to the default package.

As for the total price of customized packages, the average total price of the final customization package based on the luxury package (downgrade condition) was $7060.48 ¥$, whereas the average total price of the final customized package based on the economic package (upgrade condition) was $6318.00 ¥$. The difference is $742.48 ¥$ which was also significant $(t=4.24, p<0.001)$. The results supported $\mathrm{H} 2$. 


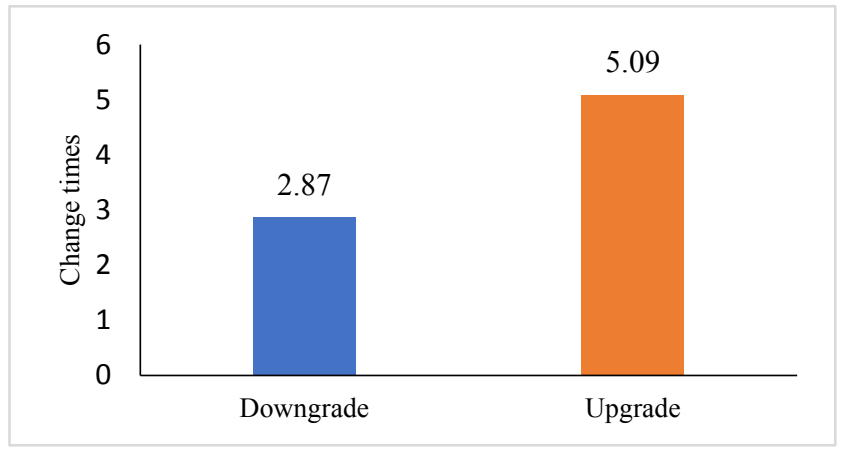

Figure 6. Change Times under Different Framing Approach

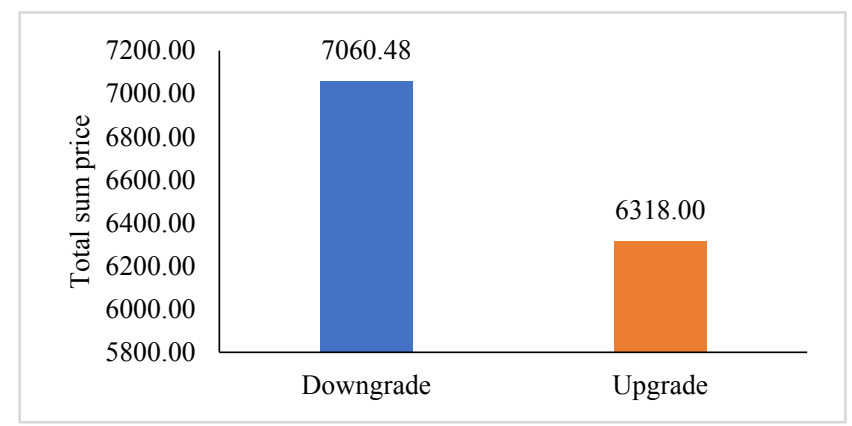

Figure 7. Total sum price of package under different framing approach

Finally, there is no significant difference in satisfaction to the decision-making process ( $M$ downgrade $=1.81$ vs. $M$ upgrade $=1.91, t=-0.65, p>0.5)$, result satisfaction $(M$ downgrade $=1.85$ vs. $M$ upgrade $=1.89, t=-0.23, p>0.8)$ and recommendation willingness $(M$ downgrade $=1.98$ vs. $M$ upgrade $=2.07, t=-0.46, p>0.6)$. This shows that although the service customization method can affect the final sum price of package, it has no effect on consumer satisfaction and recommendation willingness.

Table 5. Main Results in Study2

\begin{tabular}{cccccc}
\hline $\begin{array}{c}\text { Framing } \\
\text { approach }\end{array}$ & $\begin{array}{c}\text { Change } \\
\text { times }\end{array}$ & $\begin{array}{c}\text { Total } \\
\text { sum } \\
\text { price }\end{array}$ & $\begin{array}{c}\text { Satisfaction } \\
\text { to process }\end{array}$ & $\begin{array}{c}\text { Satisfaction } \\
\text { to results }\end{array}$ & $\begin{array}{c}\text { Recommendation } \\
\text { intention }\end{array}$ \\
\hline Downgrade & 2.87 & 7060.48 & 1.81 & 1.85 & 1.98 \\
Upgrade & 5.09 & 6318.00 & 1.91 & 1.89 & 2.07 \\
& $t=5.42$ & $t=4.24$ & $t=0.65$ & $t=0.23$ & $t=0.46$ \\
Significance & $p<$ & $p<$ & $p>0.5$ & $p>0.8$ & $p>0.6$ \\
& 0.0001 & 0.0001 & $p$ & & \\
\hline
\end{tabular}

Furthermore, we also examined the moderating role of gender. In terms of package prices, although the covariance results showed that there was no interaction between the framing approach (downgrade vs. upgrade) and gender $(F$ $(1,113)=1.45, p>0.2)$. However, after dividing the data separately, it was found that in the male participants, the price difference between the degraded condition and the upgraded condition was significant $(M$ downgrade $=$ 6975.24 vs. $M$ upgrade $=6113.06, t=4.36, p<0.001$ ). In the female participants, the price difference between the downgraded condition and the upgraded condition was not significant $(M$ downgrade $=7239.50$ vs. $M$ upgrade $=$ $6817.50, t=1.32, p>0.1$ ). That is to say, for female subjects, the total price of the customized package is high both in degrade and upgrade framing approach and gender has no moderating effects on the effect of customization framing approach on total customization price. 
Table 6. Moderation Effects Results

\begin{tabular}{ccccc}
\hline $\begin{array}{c}\text { Framing } \\
\text { approach }\end{array}$ & \multicolumn{2}{c}{ Package price } & \multicolumn{2}{c}{ Package price } \\
& Male & Female & $\begin{array}{c}\text { High } \\
\text { consumption }\end{array}$ & $\begin{array}{c}\text { Low } \\
\text { consumption }\end{array}$ \\
\hline Downgrade & 6975.24 & 7239.50 & 7423.57 & 6761.47 \\
Upgrade & 6113.06 & 6817.50 & 6709.66 & 5881.15 \\
Significance & $t=4.36$ & $t=1.32$ & $t=3.48$ & $t=3.62$ \\
& $p<0.001$ & $p>0.1$ & $p<0.0001$ & $p<0.0001$ \\
Moderation & $F(1,113)=1.45, p>0.2$ & $F(1,113)=0.27, p>0.6$ \\
\hline
\end{tabular}

In terms of customized package prices, we divided the monthly consumption of less than 10,000 yuan into a low-consumption group, and that more than 10,000 yuan into a high-consumption group. The covariance results show that there is no moderation effect of consumption level (high vs. low) on the effect of framing approach on package price $(F(1,113)=0.27, p>0.6)$. No matter in high-consumption subjects $(M$ downgrade $=7423.67$ vs. $M$ upgrade $=6709.66, t=3.48, p<0.001)$ or low-consumption subjects $(M$ downgrade $=6761.47$ vs. $M$ upgrade $=$ $5881.15, t=3.62, p<0.001$ ), the package price under downgrade framing is significantly higher than that under upgrade framework.

\section{Discussion and Implication}

To summarize, two experiments provided consistent evidence for the influence of framing effects on consumer decision-making in the context of online shopping and travel customization. Study1 examined the impact of different pricing strategies (partitioned pricing vs. combined pricing) on consumer decision-making especially on purchase intention. It was found that compared with the partitioned pricing strategy when the e-commerce platform adopts the combined pricing strategy, consumers are more willing to purchase the product. Study2 examined the impact of two different travel customization framing approach (downgrade framing vs. upgrade framing) on consumer decision making process on customer service customization behavior process and total sum price of the travel package. The results showed that compared with the upgrade customization method based on the low-level package, when the online travel agency adopts the downgrade customization framing approach based on the advanced package, the total sum price is higher.

This research has important practical implications for both marketers and consumers. Firstly, for e-commerce platforms, they should adopt combined a pricing strategy when selling products rather than partitioned pricing methods. It's better for them to provide a total price that includes product cost itself and other fees like postage, packaging fee and so on. By doing that, marketers can help to reduce the pain of consumers when paying. It not only can improve consumers' purchase, but also enhance their consumption happiness, which ultimately improves consumer satisfaction and loyalty. Secondly, according to the results in study 2 , consumers can easily customize the package with a high total sum price. Therefore, from the purpose of maximizing profit, online service customization platforms (such as travel, beauty or fitness) should recommend the luxury package as a base model as much as possible. It is worth noting that even if the use of framing effects can bring higher profits to marketers, companies should not excessively pursue the irrational use of consumers to make profits. If the consumer recognizes his or her intention, the effect will backfire.

For consumers, this study can help consumers to more clearly understand their behavioral habits and thinking limitations in the online shopping environment and online service customization. Both consumers and firms suffer from financial constraints (Guo \& Luo, 2017). Consumers are often irrational in their decision-making and are easily to be influenced by the product/service framing approach. Therefore, consumers should try to avoid falling into the business traps in service customization or other purchase decisions and reduce unnecessary consumption. For example, when customizing service, consumers should choose to upgrade the service based on low-grade package so as to meet their own needs and save money.

Definitely, the current research has some limitations. First, the results were only based on the setting of online purchases of electronics and online travel customization in study 1. Future research needs to explore product categories. Second, the dependent variable in Study 2 was only measured using custom price, which is relatively 
limited. Future research needs to discuss whether consumers prefer to customize from a low-level service package or high-level service package.

\section{Acknowledgements}

The authors appreciate the helpful comments from Dr. Wenjing (Maggie) Liu and Dr. Yafeng Fan at School of Economics and Management, Tsinghua University, China.

\section{References}

Bruno, H., Che, H. \& Dutta, S. (2012). Role of reference price on price and quantity: Insights from Business-to-Business markets. Journal of Marketing Research, 49(Oct.), 640-654. https://doi.org/10.1509/jmr.09.0334

Dong, Z. Y. (2006). Principles of Behavioral Economics. Beijing: Peking University Press.

Ghoshal, T., Yorkston, E., Nunes, J.C., \& Boatwright, P. (2014). Multiple reference points in sequential hedonic evaluation: An empirical analysis. Journal of Marketing Research, 51(Oct.), 563-577. https://doi.org/10.1509/jmr.12.0075

Guo, Z. Y., \& Luo, Y. (2017). Credit constraint exports in countries with different degrees of contract enforcement. Business and Economic Research, 7(1), 227-241. https://doi.org/10.5296/ber.v7i1.10923

Jin L., \& Zou D. (2009). Additive or subtractive, upgrade or downgrade: Self-selected framing and service package customization. Chinese Journal of Marketing Science, 5(4), 115-126.

Khan, U. \& Dhar, R. (2010). Price-Framing effects on the purchase of hedonic and utilitarian bundles. Journal of Marketing Research, 47(6), 1090-1099. https://doi.org/10.1509/jmkr.47.6.1090

Kahneman, D., \& Tversky, A. (1979). Prospect theory: An analysis of decision under risk, Econometrica, 47, 263-291. https://doi.org/10.2307/1914185

Levin I. P., \& Gaeth G. J. (1988). How consumers are affected by the framing of attribute information before and after consuming the products. Journal of Consumer Research, 15(3), 374-378. https://doi.org/10.1086/209174

Liu, T., Xu F., Zhang, J., Jiang D., \& Chen X. (2010). The Psychological mechanism and influential factors of endowment effect. Advances in Psychological Science, 18(4), 646-654. http://journal.psych.ac.cn/xlkxjz/EN/Y2010/V18/I04/646

Mittelman, M., Andrade, E.B., Chattopadhyay, A.\& Brendl, C. M. (2014). The offer framing effect: Choosing single versus bundled offerings affects variety seeking. Journal of Consumer Research, 41(December), 953-964. https://doi.org/10.1086/678193

Park, C. W., Jun, S. Y., \& Macinnis, D. J. (2000). Choosing what I want versus rejecting what I do not want: An application of decision framing to product option choice decisions. Journal of Marketing Research, 37(2), 187-202. https://doi.org/10.1509/jmkr.37.2.187.18731

Peng, L., Sun, L., \& Peng, S. (2012). "20\% Off” or "7 Zhe”? A regulatory fit explanation of the discount framing $\begin{array}{lllll}\text { effect. } & \text { Journal }\end{array}$ http://www.jms.org.cn:8081/jms/CN/volumn/volumn_1138.shtml

Thaler R. (1985). Mental accounting and consumer choice. Marketing Science, 4(3), 199-214. https://doi.org/10.1287/mksc.4.3.199

Thaler R. (1980). Towards a positive theory of consumer choice. Journal of Economic Behavior and Organization, 1(1), 39-60. https://doi.org/10.1016/0167-2681(80)90051-7

Thaler, R. H., \& Sunstein, C. R. (2008). Nudge: Improving decisions about health, wealth and happiness. New Haven, CT: Yale University Press. https://psycnet.apa.org/record/2008-03730-000

Tversky A. \& Kahneman D. (1981). The framing of decision and the psychology of choice. Science, 211(30, January), 453-458. http://science.sciencemag.org/content/211/4481/453

Zhang, L., Tu Y., \& Zhang, S. (2008). The effect of mode of thinking on the perception of partitioned pricing and combined pricing. Proceedings of Annual Conference of Journal of Marketing Science in 2007, 351-359. 